\title{
UMA VISÃO CRÍTICA ACERCA DA IMPORTÂNCIA DA MEDIAÇÃO DE CONFLITO E DA JUSTIÇA RESTAURATIVA E SUA APLICABILIDADE NO ÂMBITO PENAL.
}

Beatriz Guimarães Cabral, Weslley Neponuceno de Paula, Pablo Rodrigo França.

Universidade do Oeste Paulista - UNOESTE, Curso de Direito, E-mail:this guimaraes@hotmail.com Graduando em Direito. UNOESTE.

\section{RESUMO:}

Uma importante visão acerca do quão a Mediação Penal, bem como a Justiça Restaurativa podem ser ferramentas "inovadoras" para solução de conflitos, dando total desnecessidade de um prolongamento em juízo. E, a Mediação, sempre visando para as partes envolvidas oportunidades interessantes, para que ambas tentem resolver o conflito, unindo-as de um modo brando, através de uma conversa conciliadora. No âmbito penal, órgãos mediadores, como Necrim e Jecrim são exemplos para a reparação de conflitos de menor potencial ofensivo, tentando-se chegar a uma Justiça Criminal de interesses propriamente dita.

Também é de se ressaltar os benefícios que a Mediação Penal pode proporcionar para as partes envolvidas, como também para a sociedade. Sempre com o intuito da humanização no sistema penal e facilitação de conflitos.

PALAVRAS CHAVES: Mediação. Justiça. Solução. Jeecrim. Necrim.

\section{A CRITICAL VIEW ABOUT THE IMPORTANCEOF CONFLICT MEDIATION AND RESTORATIVE JUSTICE AND HER APPLICABILITY IN CRIMINAL SCOPE.}

\begin{abstract}
An important insight about how the Criminal Mediation and Restorative Justice can be "innovative" tools for conflict resolution, giving full no need for an extension in court. And mediation, always aiming for the parties involved interesting opportunities so that both try to resolve the conflict, uniting them in a mild way, through a conciliatory conversation. In criminal matters, mediators organs such as Necrim and JECrim are examples for the repair of conflicts of minor offensive potential, by trying to reach a proper criminal justice interests.

It is also to highlight the benefits the Criminal Mediation can provide to the parties involved, but also for society. Always with the aim of humanizing the penal system and facilitating conflict.
\end{abstract}

KEYWORDS: Mediation. Justice. Solution. Jeecrim. Necrim. 


\section{INTRODUÇÃO:}

O presente artigo diz respeito aos novos paradigmas da prática da Justiça Restaurativa e da Mediação Penal, esta por sua vez é um acordo entre as partes diante de um litigio ocorrido, a mesma vem crescendo em porcentagem, e é considerada de suma importância, pois traz vários benefícios, um deles é o potencial ao qual contribui para a redução da reincidência.

A mediação penal possui benefícios para a sociedade, vitima, e para o réu, seu intuito é cooperar para o entendimento das partes, de uma maneira mais branda que seja benéfica a todos, como por exemplo: promove o envolvimento de todos no conflito, direta e indiretamente, promovendo o exercício da cidadania; contribui para a vítima participar diretamente na resolução do conflito que a atingiu; auxilia o réu a reparar a vítima participando da solução do conflito, respectivamente. Analisaremos com mais precisão cada item no decorrer do desenvolvimento deste trabalho.

Por fim, serão apresentados casos verídicos ao qual é cabível a mediação penal. Porém em todos os casos é necessário que ambas as partes queiram, não sendo possível que haja mediação com apenas uma das partes. Caso a primeira tentativa não fora realizada com sucesso, há possiblidade de uma nova tentativa, isso, nos casos de mediação.

\section{OBJETIVO GERAL:}

Compreender a importância da Justiça Restaurativa no âmbito penal, a sua contribuição em reduzir o número de ação penal, bem como o acordo entre as partes envolvidas, não somente o réu e a vítima como também a sociedade.

\section{OBJETIVO ESPECÍFICO:}

- $\quad$ Conhecer como funciona a Mediação Penal;

- $\quad$ Compreender como é realizado a Justiça Restaurativa e prática restaurativa;

- $\quad$ Obter informações a respeito dos benefícios para o réu, vítima e sociedade;

- $\quad$ Analisar casos reais, pertencentes à Justiça Restaurativa.

\section{METODOLOGIA:}

Para desenvolver este trabalho utilizamos o método de pesquisa bibliográfica, onde buscamos autores que desenvolveram seus estudos e pesquisas quanto a Mediação de Conflito no âmbito penal, bem como a prática da Justiça Restaurativa.

Partindo do principio de atuação pratica quanto a Mediação, analisamos os métodos de atuação de órgãos mediadores de conflitos, como Necrim do município de Presidente Venceslau SP, e o Juizado Especial Criminal (Jecrim) do município de Mirante do Paranapanema - SP.

A Mediação decorrente na esfera penal, abrangendo litígios de menor potencial ofensivo é o ponto chave de tais órgãos, focando em não deixar mais saturado ainda o Poder Judiciário e visando uma facilidade a todos aqueles envolvidos ao caso, para a solução do mesmo.

\section{MEDIAÇÃO}

A mediação,método não adversarial de gestão de conflitos, constitui um marco nas relações interpessoais porque demonstra a fragilidade de soluções impostas e a inutilidade do rancor como substituto às decisões temperadas pelo bom-senso.

A Justiça Restaurativa, através da mediação penal, surge para a construção de um novo paradigma de justiça penal efetivando o Estado Democrático de Direito através da dignidade da pessoa humana, do acesso à justiça, do exercício da cidadania e da concretização de outros princípios constitucionais. 


\section{A MEDIAÇÃO PENAL}

No ramo penal, o foco da mediação são as consequências do crime e as relações sociais afetadas pela conduta.A mediação penal consiste no processo informal e flexível, onde se insere a figura de um terceiro imparcial - mediador - que age com a finalidade de recompor um conflito originado de um ato delituoso. O mediador desenvolve seu trabalho em uma posição neutra, tentando obter o melhor das partes, promovendo a aproximação destas sem impor soluções. Mas, conduzindo o processo na tentativa de ajudar as pessoas a restabelecerem o diálogo e sugerindo que encontrem uma solução satisfatória para todos.O Ministério Público recebe a ação penal onde analisa a gravidade do crime para propor uma tentativa de acordo entre as partes. Estas aceitando a possibilidade de acordo são entrevistadas separadamente. A vítima diz o que sentiu, o quão foi afetada e como quer que o dano seja reparado. O réu conta o que motivou a realização do crime e o que está disposto a fazer para reparar o dano causado. Logo, ambos se encontram e com a ajuda do mediador tentam chegar a um acordo. Em caso negativo, há o acionamento judicial.

\section{BENEFÍCIOS DA MEDIAÇÃO PENAL}

Os benefícios da mediação penal atingem tanto ao infrator,a vítima e a sociedade.

a) Benefícios para o infrator:

- conscientizarde suas ações e das consequências das mesmas sobre a vítima, a comunidade e sobre si mesmo;

- reparar a vítima participando da solução do conflito;

- valoriza ao delinquente a partir do momento que reconhece sua capacidade de se responsabilizar e lhe oportuniza participar da resolução do conflito e agir em conformidade com a lei;

O processo de mediação penal reduz o tratamento discriminatório impingido pelo direito penal ao infrator, restabelecendo a dignidade humana e deixando de considerá-lo como "inimigo", isto é, deixando de considerar o infrator como aquele responsável por todos os males da sociedade.

b) Benefícios para a vítima:

- participar diretamente na resolução do conflito que a atingiu;

- possibilidade de expressar seus sentimentos, bem como seu ponto de vista em relação ao conflito;

- possibilidade de relatar ao infrator e à comunidade o impacto que a infração teve na sua vida, tanto no âmbito material quanto psicológico;

c) Benefícios para a sociedade:

- a mediação penal é um instrumento apto a produzir a transformação comunicativa, gerando relações com maior cunho de respeitabilidade nas comunidades em que são implantadas reduzindo, assim, o índice de violência;

- a mediação promove o envolvimento de todos no conflito, direta e indiretamente, promovendo o exercício da cidadania;

- a mediação penal fomenta a busca de interesses comuns que favoreça a convivência e previna a criminalidade, em vez de estigmatizar e reforçar as diferenças entre os membros da comunidade.

\section{JUSTIÇA RESTAURATIVA E PRÁTICA RESTAURATIVA}


Justiça restaurativa consiste em um paradigma não punitivo baseado em valores, que tem como principal objetivo a reparação dos danos oriundos do delito causados às partes envolvidas vítima, ofensor e comunidade - e, quando possível, a reconstrução das relações rompidas.

Processos restaurativos seriam aqueles nos quais vítimas, ofensores e, quando apropriado, outros indivíduos ou membros da comunidade afetados pelo crime participam juntos e ativamente na resolução das questões provocadas pelo injusto geralmente com a ajuda de um facilitador - uma terceira pessoa independente e imparcial, cuja tarefa é facilitar a abertura de uma via de comunicação entre as partes, apenas alimentando o diálogo.

Resultados restaurativos, por sua vez, seriam os acordos resultantes dos processos, que podem incluir a reparação do dano, a restituição de algum bem e a prestação de serviços à comunidade, visando à reintegração da vítima e do ofensor.

Quanto à participação dos envolvidos, é preciso garantir a maior colaboração das vítimas e também da comunidade. Para a vítima, já é consenso nos programas à necessidade de criação de um serviço de apoio. Com relação à comunidade, é preciso ampliar sua participação nos círculos/encontros restaurativos. Por meio da vizinhança, família, amigos, etc. Potencialmente contribui para a redução da reincidência.

\section{RECOMENDAÇÕES PARA OS PROGRAMAS DE JUSTIÇA RESTAURATIVA EM GERAL:}

$\checkmark \quad$ Criar serviço de apoio à vítima;

$\checkmark$ Quanto ao acordo, prever a realização de uma nova tentativa em caso de descumprimento;

$\checkmark \quad$ Ampliar o momento de preparação das partes para o círculo/encontro restaurativo;

$\checkmark \quad$ Ampliar a participação da comunidade nos círculos/encontros restaurativos;

\section{CASOS REAIS QUE GOZAM DO AUXÍLIO DA MEDIAÇÃO}

Jecrim:Os Juizados Criminais (Jeecrim) são órgãos da Justiça que julgam infrações penais de menor potencial ofensivo, buscando-se, com rapidez, a reparação do dano sofrido pela vítima, a suspensão condicional do processo e, em último caso, uma possível condenação.

Espécies: Vias de fato (Contravenções Penais - art. 21) e Ameaça (art. 147).

Compareceu na DelPol de Mirante do Paranapanema, José, declarando que quando fazia caminhada, o autor Osvaldo que trabalha na CONAB - Companhia Nacional de Abastecimento, da mesma cidade parou a vítima na rua e desferiu um tapa em seu rosto, e ainda disse que iria matálo e sua família. A vítima declara que a única pessoa que viu os fatos foi à mulher de Osvaldo. A vítima alega que Osvaldo trabalha na CONAB e toda vez que vai pegar os alimentos que são entregues gratuitamente para a população, Osvaldo sempre deixava de entregar o seu, motivo esse que José fez denuncia na Prefeitura Municipal, onde causou raiva do autor. A vítima foi cientificada do prazo decadencial de 06 (seis) meses para representar contra o autor dos fatos, nos termos da lei 9099/95. Nada mais.

Necrim:O Núcleo Especial Criminal (NECRIM) vem auxiliar o poder judiciário, servindo como um instrumento que além de solucionar pequenos conflitos, desafoga o Poder Judiciário e as atividades da Policia Judiciária, dando oportunidade para que o Delegado de Policia e suas equipes possam se dedicar mais aos Inquéritos Policiais e à apuração de crimes de maior potencial ofensivo.

Espécies: Lesão corporal culposa na direção de veículo automotor.

No dia 18 do mês de fevereiro de 2016, às 15h30min, no Núcleo Especial Criminal de Presidente Venceslau/SP, onde presente se achava o Delegado de Polícia, Dr. Everson, compareceram Eder e Isaias, tendo em vista que envolveram-se em um acidente de trânsito, que subsidiou a instauração do presente Termo Circunstanciado.À Autoridade Policial orientou as 
partes sobre a finalidade e a possibilidade da composição preliminar, bem como sobre suas consequências legais, enfatizando a importância de se buscar uma solução de consenso. A seguir, a Autoridade Policial deu a palavra a Eder, o qual declarou que em relação aos fatos narrados no B.O informa que na data dos fatos estava transitando com sua motocicleta pela Rua Campos Sales, sentido Jardim Arantes e o veículo Fox, conduzido por Isaias transitava na Rua Almirante Barroso, e na confluência das duas vias ocorreu à colisão. Do evento sofreu lesões corporais leves e suportou danos na sua motocicleta avaliados em $\mathrm{R} \$ 300,00$.

Após, a Autoridade Policial deu a palavra a Isaias, o qual ratifica as declarações de Eder. Que do evento não sofreu lesões corporais e seu veículo teve danos avaliados em $\mathrm{R} \$ 2.150,00$.

\section{CONCLUSÃO:}

Tanto a Mediação Penal, como a Justiça Restaurativa, é um novo caminho na Justiça Criminal, visando sempre trazer uma facilidade para com os envolvidos no conflito, e fazendo com que isso reflita na sociedade em geral.

O modelo restaurativo se destaca "como fundamento de uma nova subjetividade que atribua aos indivíduos um papel ativo, de redefinição dos problemas, de reafirmação da própriaesfera de autonomia e poder, seja em termos culturais, políticos, psicológicos (...)." (Leonardo Sica, 2007; p. 19).

A Mediação Penal, como instrumento da Justiça Restaurativa, surge como "novo" paradigma contribuindo para a humanização do sistema penal.

Por fim, é importante ressaltar que a Justiça Restaurativa "não é um modelo substitutivo ao atual: os modelos punitivos e restaurativos devem coexistir e complementar-se, (...)." (SICA, 2007, p.34).

\section{REFERÊNCIAS BIBLIOGRÁFICAS:}

FIORELLI, José Osmir, Maria Rosa e MALHADAS, Marcos JulioOlivé Junior. Mediação e Solução de Conflitos. 2008. Editora Atlas. - São Paulo.

SICA, Leonardo. Justiça Restaurativa e Mediação Penal: O Novo Modelo de Justiça Criminal e de Gestão de Crime. 2007. Editora Lumen Juris - Rio de Janeiro.

VASCONCELOS, Carlos Eduardo de. Mediação de Conflitos e Práticas Restaurativas. 2008. Editora Método - São Paulo.

https://aplicacao.mpmg.mp.br/xmlui/bitstream/handle/123456789/1106/6\%20R\%20Mediacao\%2 Openal\%20-\%20ana\%20paula.pdf?sequence=1 Acesso em 05 mai. 2016.

http://www.mediarconflitos.com/2007/10/mediao-no-direito-penal.html Acesso em 05 mai. 2016.

http://www.tribunavirtualibccrim.org.br/artigo/11-Justica-Restaurativa:-um-novo-modelo-deJustica-Criminal Acesso em 05 mai. 2016. 